\title{
O ENSINO DE FILOSOFIA NO CONTEXTO BIOPOLÍTICO
}

\author{
Katiuska Izaguirry Marçal"
}

\section{Introdução}

Este artigo é parte da dissertação "Filosofia na escola: a constituição da disciplina a partir das práticas docentes”. Conforme o título pretende indicar, demarcou-se em tal pesquisa um lócus de investigação: a escola. Neste sentido, destaca-se a atualidade do problema relativo à efetivação da filosofia no âmbito de um espaço que pretende "transmitir" conhecimentos e modos de ser próprios da sociedade contemporânea. A escola, portanto, é compreendida enquanto instituição normalizadora e constitui um mecanismo de objetivação dos sujeitos que funciona através de determinadas estratégias de poder.

Por conseguinte, o saber filosófico que interessou, neste trabalho, diz respeito a sua condição enquanto saber submetido à "ordem do discurso" escolar e, portanto, passível de análise discursiva, conforme a perspectiva foucaultiana. Além disso, buscou-se compreender como se constitui a filosofia, na escola, a partir das "práticas docentes". Por práticas, entendam-se tanto os discursos como os fazeres pedagógico-filosóficos dos sujeitos professores ${ }^{1}$. Neste sentido, o exercício de análise arquegenealógica empreendido na pesquisa abarca os enunciados proferidos pelos professores, assim como suas práticas pedagógicas cotidianas. Tais elementos - discursivos e não discursivos - são, pois, produtores e, ao mesmo tempo, efeitos de uma rede relacional complexa de poderes e saberes.

Em determinado momento da pesquisa, foi importante observar mais atentamente a relação entre as formações discursivas e o espaço institucional escolar. Assim, efetivou-se a análise dos enunciados estabelecidos nas políticas

\footnotetext{
Mestra em Educação pela Universidade Federal de Santa Maria. E-mail: katiuskaizaguirry@gmail.com.

${ }^{1}$ A pesquisa efetivou-se a partir de entrevistas individuais semi-estruturadas realizadas com seis professores formados em cursos de Licenciatura em Filosofia e atuantes na disciplina de filosofia, no ensino médio.
}

MARÇAL, Katiuska Izaguirry. O ensino de filosofia no contexto biopolítico. Por un diagnóstico de nuestro presente educacional. Revista Sul-Americana de Filosofia e Educação. Número 20: maio-out/2013, p. 107-119. 
públicas referentes ao ensino de filosofia e seus efeitos nas práticas discursivas e não discursivas dos professores entrevistados. $\mathrm{O}$ presente texto expõe este momento de leitura das políticas públicas educacionais e suas implicações para o ensino de filosofia institucionalizado. Por fim, elabora uma breve reflexão sobre as possibilidades de constituir a disciplina de filosofia como um espaço de resistência, mesmo que dentro de um contexto discursivo e institucional que remeta a sua função de conformadora social.

\section{A escola como espaço do discursivo e do não-discursivo}

A concepção de que as políticas de Estado constituem efeitos no cotidiano escolar tem como pressuposto a ideia de que não há oposição entre o discursivo $e$ o não-discursivo. Por conseguinte, entende-se que tais elementos são os agentes de disciplina e controle social que fazem funcionar a escola enquanto instituição conformadora de sujeitos "aptos" a viver e produzir na sociedade.

Sobre a relação intrínseca entre discurso e prática, ou ainda, sobre a noção de que os discursos são também práticas a constituir o modelo instituicional escolar, pode-se afirmar, nas palavras de Deleuze (1988) que há complementaridade entre o enunciável (discurso) e o visível (práticas, sujeitos, materialidades). Neste sentido, o modelo de análise proposto por Foucault estabelece três formas de relação a partir do enunciado: o espaço colateral, que constitui as formações discursivas e do qual fazem parte apenas enunciados; o espaço correlativo, que trata da relação dos enunciados com seus sujeitos, objetos e conceitos'; e, finalmente, o espaço complementar, que estabelece "relaçóes

\footnotetext{
${ }^{2}$ Deleuze esclarece, no texto Um novo arquivista, as diferenças entre o sujeito, objeto e conceito nas frases e proposições e esses elementos, nos enunciados. "Se os enunciados se distinguem das palavras, frases e proposições é porque eles englobam, como seus derivados tanto as funções de sujeito como as de objeto e de conceito. Precisamente: sujeito, objeto, conceito são apenas funções derivadas da primitiva ou do enunciado. Assim, o espaço correlativo é a ordem discursiva dos lugares ou posições dos sujeitos, dos objetos e dos conceitos numa família de enunciados. [...] Ao sistema de palavras, frases e proposições, que procede por constante intrínseca e variável extrínseca, opõe-se então a multiplicidade dos enunciados, que procede por variação inerente e por variável intrínseca." (DELEUZE, 1988, p. 19-21). Fundamentalmente, sujeito, objeto e conceito, ao constituírem um enunciado, deixam de exigir referente, estado de coisas ou intencionalidade externa ao próprio enunciado.
} 
discursivas com meios não discursivos" (DELEUZE, 1988, p. 21). Tal modo de relação é o que acontece nos espaços institucionais.

Uma instituição comporta ela mesma enunciados, por exemplo, uma constituição, uma carta, contrato, inscrições e registros. Inversamente, os enunciados remetem a um meio institucional sem o qual os objetos surgidos nesses lugares do enunciado não poderiam ser formados, nem o sujeito que fala de tal lugar (por exemplo, a posição do escritor numa sociedade, a posição do médico no hospital ou em seu consultório, em determinada época, e o surgimento de novos objetos). (Ibidem)

O espaço complementar se constitui na medida em que não há anterioridade entre os aspectos discursivos e não-discursivos e, além disso, "as duas formações são heterogêneas, apesar de inseridas uma dentro da outra: não há correspondência nem isomorfismo, não há causalidade direta nem simbolização." (Ibid., p. 41). No caso desta pesquisa, a escola e a disciplina de filosofia compõem-se de enunciados e práticas (pedagógicas, políticas, filosóficas) que estabelecem o lugar dos sujeitos que falam sobre elas (professores) $e$ demarcam entre si as formas de saber e de fazer. A escola é condição desta complementaridade. Por conseguinte, apesar de tratar eminentemente de uma análise discursiva, nesta pesquisa não se pode esquecer a correlação entre os enunciados que atravessam os discursos dos professores e dos documentos oficiais $e$ as características disciplinares e de controle próprias de nosso tempo.

A escola, enquanto instituição que serve a determinados propósitos sociais e políticos, engendra e põe em funcionamento determinadas técnicas que submetem alunos e docentes. Portanto, é pertinente observar mais detalhadamente outros elementos - para além das concepções filosóficas e de ensino dos professores que conformam as práticas pedagógicas, no espaço escolar às normas desta instituição em particular. Para tanto, propõe-se a leitura mais atenta de algumas políticas educacionais do Estado.

\section{Escola, tecnologias de subjetivação e governamentalidade}

A situação institucional em que se encontram os professores entrevistados pode explicitar muito da constituição de suas práticas de ensino $e$ as consequentes disparidades entre elas e os objetivos filosóficos e educacionais que propõem. Há, 
por um lado, a necessidade de formar pessoas produtivas para o mercado de trabalho e uma atuação em sociedade e, neste sentido, precisa-se estabelecer as continuidades entre os discursos escolares e as normatizações do Estado. De outro modo, percebe-se a correlação entre as práticas, discursivas e não-discursivas, e a necessidade de controle e disciplinamento dos estudantes (manter seu interesse pelos saberes escolares, fazer com que valorizem o conhecimento, fazer compreender a utilidade da filosofia para sua conduta cotidiana, etc.).

Cerletti (2009) conta um pouco da história do processo de conformação da filosofia ao âmbito institucional, na Argentina, $e$ as consequências deste movimento. Ele atenta que justamente este processo, marcado pela ocupação dos programas escolares oficiais é que dá início à separação entre produção e transmissão filosóficas. O ensino de filosofia, portanto, passa a ser competência do Estado e assim:

Os mestres ou professores já não transmitem uma filosofia - ou a sua filosofia. Mas agora, para além do grau de liberdade que tenham para exercer esta atividade, ensinam "Filosofia" de acordo com os conteúdos e critérios estabelecidos pelos planejamentos oficiais e pelas instituições habilitadas para tal. (p. 13)

Sob tal condição, o questionamento filosófico (ou a radicalidade do pensamento) encontra limites à sua circulação em prol da necessidade de assegurar o laço social. O Estado cumpre politicamente essa função geral reguladora, que tende a garantir a continuidade daquilo que liga cotidianamente, através das disposições, das normas, das direções escolares e também através dos mestres e professores, que nisso operam como "funcionários" de tal Estado. (Ibid., p. 69) Não obstante, o caráter moderno da escola permanece, segundo Cerletti, na relação entre aquisição de conhecimentos e a promoção da liberdade, e, "em especial, atualiza permanentemente a tensão entre "educar" para exercer a soberania (forjar sujeitos livres) e exaltar a necessidade da obediência (promover indivíduos governáveis)." (Ibid., p. 70)

Relativamente ao espaço da conformação social, nos currículos escolares, ressaltam-se as reformas educacionais ocorridas na década de noventa nos países latino-americanos, sob a égide das reformas espanholas. Neste contexto insere-se a 
própria LDB, que pretende uma "formação ética e cidadã" e indica a "decisão política de enlaçar filosofia, educação e Estado com um sentido utilitário de acordo com a tônica dos tempos de reformas neoliberais." (CERLETTI, 2009, p. 71) "A vontade de construção simultânea de uma "formação ética" e uma "formação cidadã" mostra, mais que uma preocupação filosófica, uma intencionalidade prática de constituir um vínculo essencial entre ética e política, baseado fundamentalmente nas ações e decisões individuais, mais do que nas coletivas." (Ibidem) A coincidência entre as pretensões dos professores e as decisões da legislação surpreendem, mas encontram-se na manutenção do ideal moderno de autonomia a partir do conhecimento. Entretanto, como bem ressalta Cerletti, nas disposições do Estado, este ideal se entrelaça com as questões de governamentalidade. Cidadania e ética constituem, pois, elementos condizentes com os ideias empresariais em voga. Não obstante os professores terem em conta esta crítica, eles mantêm seu discurso em consonância com os objetivos oficiais.

Maria Isabel Bujes (2002) compreende a legislação como uma tecnologia de subjetivação. O sentido que a autora atribui à tecnologia é o mesmo proposto por Rose:

\begin{abstract}
A tecnologia refere-se, neste caso, a qualquer agenciamento ou a qualquer conjunto estruturado por uma racionalidade prática $e$ governado por um objetivo mais ou menos consciente. As tecnologias humanas são montagens híbridas de saberes, instrumentos, pessoas, sistemas de julgamento, edifícios e espaços, orientados, ao nível programático, por certos pressupostos e objetivos sobre os seres humanos. (ROSE, 1996 a: 26 apud BUJES, p. 164)
\end{abstract}

As políticas públicas, tomadas como tecnologias de subjetivação, têm por condição a governamentalidade. Foucault (1979) desenvolve este conceito ao investigar a história da tríade "segurança-população-governo". Neste sentido, governamentalidade diz respeito à produção de tecnologias relativas à população $e$ têm como momento de emergência, o período da Modernidade. O governo, até então, era tido como a arte própria ao soberano (concernente aos modos de comportamento, a melhor forma de exercer o poder, às formas de manter a obediência dos súditos, etc.). A partir do século XVII, através do desenvolvimento da ciência do governo e da expansão europeia, cada vez mais a economia adentra 
as questões de poder e os problemas de população tomam o espaço em detrimento da família ${ }^{3}$, tornando-se fim último do governo.

Sob o desenvolvimento do capitalismo, a nova regra de governo é a menor intervenção do Estado. Entra em cena a governamentalidade dos economistas. Conforme Lokcmann (2010), Foucault afirma um "naturalismo" em que a forma de governamentalidade pretende "respeitar as leis naturais da sociedade" em vez de regulamentá-la. Cabe ao governo, portanto, facilitar, mediar, permitir, suscitar, enfim, administrar a liberdade natural aos homens. Tais imperativos, aliás, constituem ainda hoje os discursos pedagógicos. Esta autora ainda explica que no contexto neoliberal a pergunta refere-se ao como intervir, na medida em que a intervenção torna-se necessária ao bom governo. O neoliberalismo, pois, engendra atualmente uma nova lógica, que permite, inclusive, a entrada da sociedade civil $e$ empresarial nos âmbitos regulatórios, até então, específicos dos Estados. No entanto, a governamentalidade atua no controle e produção dos desejos e das vontades dos indivíduos. Mais uma vez ela lembra o cenário escolar, atualmente "livre" para criar e executar projetos pedagógicos, no entanto, cada vez mais atrelado a avaliações institucionais de larga escala que, em última instância, irão ditar metas e regras. É neste sentido que as políticas públicas, enquanto dispositivos $^{4}$ de governo, consistem em tecnologias de subjetivação, constatáveis na escola através dos professores e estudantes.

Relativamente às aulas de filosofia, percebe-se a constante definição e busca pelos professores em constituir uma disciplina escolar que definitivamente crie condições de exercício da crítica. O debate, a opinião, a possibilidade de falar, ouvir, escrever, enfim, atividades presentes nas aulas de filosofia convergem para a

\footnotetext{
${ }^{3}$ Foucault atribui esta nova perspectiva ao desenvolvimento da ciência estatística: "De fato, se a estatística tinha até então funcionado no interior do quadro administrativo da soberania, ela vai revelar pouco a pouco que a população tem uma regularidade própria: número de mortos, de doentes, [...] revela também que a população tem características próprias [...] irredutíveis aos da família: as grandes epidemias, a espiral de trabalho e de riqueza, etc.; revela finalmente que através de seus deslocamentos, a população produz efeitos econômicos específicos. (FOUCAULT, 1979, p. 288)

${ }^{4} \mathrm{O}$ dispositivo surge nas investigações de Foucault, como conceito que delimita a perspectiva genealógica e as práticas de poder. Conforme Deleuze, o dispositivo: "É uma máquina abstrata, definindo-se por meio de funções e matérias informes, ele ignora toda a distinção de forma entre um conteúdo e uma expressão, entre uma formação discursiva e uma não-discursiva. É uma máquina quase muda e cega, embora seja ela que faça ver e falar." (1988, p. 44.)
} 
criação de um ambiente conforme os ideais democráticos e a atuação cidadã estabelecida pela LDB. Tanto os Parâmetros como as Orientações Curriculares instituem as "competências comunicativas" como objeto da filosofia. Os documentos, inclusive, dão preponderância ao desenvolvimento de formas de aprendizagem em detrimento dos conteúdos. Assim, a filosofia consiste no desenvolvimento de habilidades e competências tais como ler, escrever, tomar posição crítica, articular conhecimentos, etc. As Orientações consideram a necessidade da "história da filosofia" a formar uma estrutura de conteúdos próprios da filosofia, mas corrobora a noção de que a atividade seja o objetivo pedagógico principal na escola.

A disciplina de filosofia se consolida em meio a discussões sobre sua "utilidade". Os estudantes pouco enxergam tal utilidade e os professores insistem na possibilidade de uma intervenção crítica na vida e no mundo. Mas o que se percebe é que a utilidade, para estes sujeitos, existe em sua relação imediata com o mundo do trabalho, seja através da integração, na sociedade, de trabalhadores eficientes ou na possibilidade de inserção no ensino superior.

O poder, segundo Foucault, é condição da instituição dos saberes e das verdades. Por conseguinte, os dispositivos de governo e governamento atuam na constituição de discursos que legitimam desde saberes cotidianos até saberes científicos. A filosofia, seja como discurso de saber, seja como prática não discursiva (a de sala de aula, por exemplo) tem por condição, a vontade de verdade legitimada na e pela sociedade.

Tal vontade de verdade, [...] se reforça pela ação de um sistema institucional, ela precisa se servir de um conjunto de práticas, como a pedagogia, por exemplo, e de um sistema de apoio, como livros, bibliotecas, associações ou grupos de estudiosos, etc. Esta vontade de verdade está associada ao modo como se distribui, se valoriza, se reparte e se atribui o saber na sociedade, passando a exercer uma espécie de pressão e um poder de coerção sobre os discursos. (BUJES, 2010, p.164)

Desta forma, as políticas públicas exercem a partir do âmbito de Estado estas práticas de coação. Por outro lado, a filosofia, enquanto saber historicamente construído, tem por fundamento as questões sobre sua própria constituição. A pergunta "o que é filosofia" é filosófica em si e dela depreendem-se os mais 
diversos e contraditórios enunciados. Certamente que os enunciados acadêmicos e filosóficos, na medida em que são proferidos por especialistas são fundantes de todo e qualquer discurso sobre filosofia ou ensino de filosofia e, por conseguinte, exercem práticas pautadas neste lugar de poder que é dos especialistas.

Mas a questão que neste momento se coloca é sobre os modos como os dispositivos de governamentalidade enunciam a filosofia. Assim, se faz interessante pensar sobre os enunciados contidos nas políticas e sua correlação com as atuais concepções de filosofia que permeiam a escola e a sociedade como um todo. Vejam-se algumas considerações os documentos que, hoje, norteiam o ensino de filosofia:

a) Lei de Diretrizes e Bases, nº 9394/1996 (LDB)

O único trecho que cita a filosofia é o $\S 1^{\circ}$ do artigo 36:

Art. 36. O currículo do ensino médio observará o disposto na Seção I deste Capítulo e as seguintes diretrizes. [...]

$\S 1^{\circ}$. Os conteúdos, as metodologias $e$ as formas de avaliação serão organizados de tal forma que ao final do ensino médio o educando demonstre:

I - domínio dos princípios científicos e tecnológicos que presidem a produção moderna; II - conhecimento das formas contemporâneas de linguagem; III - domínio dos conhecimentos de Filosofia e de Sociologia necessários ao exercício da cidadania.(Grifos meus)

Na LDB, a filosofia sequer aparece como disciplina; ao lado da sociologia, é considerada um "conjunto de conhecimentos necessários ao exercício da cidadania". Este conjunto de conhecimentos, na concepção da lei, seria transversal aos conteúdos disciplinares e deveria ser "demonstrado" pelos estudantes ao final o ensino médio.

Para além das críticas - e elogios - às noções de cidadania contidas na lei e a possível ou inviável contribuição dos saberes filosóficos para tal, coloca-se em questão as condições de emergência do retorno da disciplina aos currículos brasileiros. A letra da lei reflete o momento histórico no qual o Estado, que por tanto tempo excluiu a disciplina, começa a ceder. Os pressupostos são vários: desde a luta dos professores em torno de questões trabalhistas, passando pela discussão acadêmica em favor do ensino deste conjunto de saberes como condição 
de uma formação humana plena, até a necessidade neoliberal de constituir saberes conforme seus interesses mercadológicos. No entanto, não se pode deixar de apontar a importância circunstancial de cada um destes elementos, que se intensifica a partir da promulgação da lei, mesmo sem a obrigatoriedade. ${ }^{5} \mathrm{E}$, apesar desta condição de não obrigatoriedade, a menção na LDB reforça um movimento pela consolidação, senão da disciplina, pelo menos dos conteúdos ou "saberes filosóficos". Assim, a filosofia constituirá, ao lado das disciplinas de Humanidades, uma forma de saber a ser desenvolvido e requerido nos posteriores documentos curriculares criados pelo governo.

\title{
b) Diretrizes Curriculares Nacionais do Ensino Médio (DCNEM)
}

As diretrizes apresentam propostas de regulamentação da base curricular nacional e de organização do ensino médio. São um seguimento da $\operatorname{LDB} e$, no caso da filosofia e sociologia, serviram como justificativa - rápida e não muito persuasiva - da não-obrigatoriedade. Assim, no documento, afirma-se:

\begin{abstract}
$\mathrm{Na}$ área das CIÊNCIAS HUMANAS [...] destacam-se as competências relacionadas à apropriação dos conhecimentos dessas ciências com suas particularidades metodológicas, nas quais o exercício da indução é indispensável. Pela constituição dos significados de seus objetos $e$ métodos, o ensino das Ciências Humanas e Sociais deverá desenvolver a compreensão do significado da identidade, da sociedade e da cultura, que configuram os campos de conhecimentos de História, Geografia, Sociologia, Antropologia, Psicologia, Direito, entre outros. Nesta área incluir-se-ão também os estudos de Filosofia e Sociologia necessários ao exercício da cidadania, para cumprimento do que manda a letra da lei. No entanto, é indispensável lembrar que o espírito da LDB é muito mais generoso com a constituição da cidadania e não a confina a nenhuma disciplina específica... (1998, p. 93)
\end{abstract}

A filosofia, ao lado das demais Ciências Humanas e Sociais, tem reforçado seu papel relativo à vivência social e à produção cultural pelos indivíduos. A proposta de torná-la disciplina é refutada sob o argumento da fragmentação dos conhecimentos. Ainda neste sentido, os saberes filosóficos são compreendidos como transversais a todos os outros, na medida em que os articula através das competências e habilidades que deve desenvolver.

\footnotetext{
${ }^{5}$ Apenas em 02 de junho de 2008, doze anos depois da LDB, o presidente em exercício José Alencar sanciona a obrigatoriedade das disciplinas de filosofia e sociologia.
} 
c) Parâmetros Curriculares Nacionais (PCN)

Propõem um novo perfil para o currículo, tendo em vista o que se identifica como novo ensino médio, ou seja, corrobora e justifica as noções estabelecidas na Lei. Justifica-se do seguinte modo: [...] buscamos dar significado ao conhecimento escolar, mediante a contextualização; evitar a compartimentalização, mediante a interdisciplinaridade; e incentivar o raciocínio e a capacidade de aprender. (1999, p. 04)

Desta forma, ainda compreendem a filosofia como uma espécie de competência. Estrutura o currículo conforme áreas de conhecimento - dentre as quais estão as "Ciências Humanas e suas Tecnologias" -, como se a classificação por áreas resolvesse o problema da fragmentação disciplinar. Reforçam as proposições da LDB que atrelam os conhecimentos das Ciências Humanas a "consciências críticas e criativas". Reforçam ainda, o discurso das competências e habilidades, ou seja, o desenvolvimento, através da educação, de práticas ativas e reativas ao mundo posto (sociedade civil, mercado de trabalho).

d) Orientações Curriculares para o Ensino Médio - Ciências Humanas e suas tecnologias (OCN)

Este material tem por objetivo "contribuir para o diálogo entre professor $e$ escola sobre a prática docente". Assim, empreende um debate sobre conteúdos e procedimentos didático-pedagógicos. Relata o processo de consolidação, seja institucional, nos debates éticos, na mídia, enfim o crescimento da demanda pelas discussões filosóficas na sociedade brasileira.

Mesmo ainda sem a obrigatoriedade, procurou estabelecer a especificidade dos conhecimentos filosóficos e a necessidade de constituir uma disciplina. Assim, mesmo sendo um documento oficial, empreende quase que uma discussão filosófica sobre o que seja a Filosofia. Argumenta pela necessidade de formação específica dos professores e relaciona a formação de estudantes no ensino médio aos objetivos estipulados nas diretrizes para o ensino superior. Critica as intenções da legislação brasileira em transformar conhecimentos filosóficos em meio para um 
suposto aprendizado da atuação cidadã. Não obstante as críticas às considerações da legislação sobre a filosofia, acata e justifica as noções de habilidades $e$ competências e a contribuição proeminente da filosofia em relação aos saberes sociais.

Ora, a constituição da filosofia, seja como saber ou como prática, tem no discurso efetivado pela legislação um apelo à produção de subjetividades aptas e adaptadas ao neoliberalismo. A contraposição e mesmo a negação destes valores tem por cerne a mesma matriz discursiva, o que significa, no âmbito da escola e dos discursos pedagógico-filosóficos, a reprodução constante dos termos da vontade de verdade neoliberal.

\section{Resistência como condição de liberdade}

Foucault já apontava a necessidade de formas de resistência aos discursos institucionais como única condição de atuação livre para os indivíduos. A liberdade, no entanto, é sempre imanente às condições postas pelos discursos vigentes e possíveis. Neste sentido, a prática da liberdade refere-se

[...] à luta para abrir possibilidades de novas relações para si e para os acontecimentos do mundo. A ética que [Foucault] propõe é enraizada historicamente e propugna uma autoformação como luta pela liberdade dentro dos limites de cada situação. (Eizirik, 2005, pp.143-144)

Por conseguinte, Foucault "concebe o sujeito como agônico, agonístico, no sentido de ser 'uma provocação permanente das relações poder-sabersubjetividade'." (Ibid., p.144) Neste sentido, as possibilidades de resistência dizem respeito ao exercício das relações cotidianas e micro; e a possibilidade de se engendrar "discursos menores" seria a forma de se estabelecer práticas também alternativas às instituídas pelas relações neoliberais. Disto não se depreende, portanto, a transformação definitiva dos discursos maiores e cooptantes, mas antes, a possibilidade de:

[...] invenção e pluralização de novos modos de existência, de novos mundos possíveis, com aquilo a que Gilles Deleuze e Félix Guattari designavam por 'processos de singularização', de 'micropolítica', de 'devires minoritários, num regime de conexão aberta às multiplicidades, à diferença, à alteridade. (GADELHA, 2009, p. 209)

Destaca-se, ainda neste sentido, a relação perversa empreendida pelos discursos políticos, econômicos e sociais contemporâneos. Talvez, a possibilidade 
de resistência e de autonomia em relação a estes instrumentos depreenda-se do conhecimento de como eles funcionam, atuam sobre os indivíduos. Talvez a resistência, na escola, exista na construção de outros discursos e práticas que não apenas os propostos institucionalmente. Um primeiro passo nesta perspectiva seria o fim da ingenuidade com relação aos discursos contemporâneos sobre liberdade. Lockmann (2010) explica que a estratégia, no contexto neoliberal, é tornar o sujeito sempre mais livre, sem que isto signifique sua não conformação no interior das práticas de sujeição. Conforme a autora, no contexto neoliberal:

Ser livre é saber comportar-se de acordo com determinadas regras, é saber conduzir suas próprias condutas e gerenciar com competência suas escolhas. [...] escolhas individuais que não comprometam os interesses coletivos. Sendo assim, o sujeito do neoliberalismo é responsável por si mesmo, consegue assegurar-se dos riscos a que todos estão submetidos, tem recursos para prover suas necessidades, trabalha, consome, enfim, governa a si próprio. (p. 61)

Volta-se, portanto, ao questionamento das condições sobre as quais a crítica se consolida na escola. Em que medida o trabalho empreendido nas aulas de filosofia permite o pensamento autônomo sobre si mesmo e seu tempo? A noção de autonomia levada a cabo pelos professores não se inscreve tão somente na capacidade de viver conforme os postulados econômicos e políticos deste tempo? O embate político e subversivo proposto constitui um movimento de resistência ou apenas reproduz o discurso maior das políticas neoliberais? A filosofia efetivada na escola condiz com a liberdade combativa das pequenas resistências ou com a adaptação social? Até que ponto é aceitável a consonância entre os discursos filosóficos e os biopolíticos sob a justificativa de manter a filosofia como disciplina com espaço legitimado pelos postulados neoliberais?

\section{Referências}

BRASIL. Ministério da Educação. Conselho Nacional de Educação. Câmara de Educação Básica. Diretrizes Curriculares Nacionais para o Ensino Médio. Brasilia, 1998.

BRASIL. Ministério da Educação. Secretaria de Educação Básica. Orientações Curriculares para o Ensino Médio: Ciências humanas e suas tecnologias. Brasília: 2006. 133 p. (Orientações curriculares para o ensino médio;volume 3) 
BRASIL. Ministério da Educação, Secretaria da Educação Média e Tecnológica. Parâmetros curriculares nacionais: ensino médio. Brasília: Ministério da Educação, 1999.

BRASIL. Lei de Diretrizes e Bases da Educação Nacional. Lei n ${ }^{\circ}$ 9394, de 20 de dezembro de 1996. Estabelece as diretrizes e bases da educação nacional. Brasília, DF, 1996.

BUJES, Maria Isabel E. Governando a subjetividade: a constituição do sujeito infantil no RCN/EI. Revista Pro-posições. - São Paulo. v. 13, n. 1(37), p. 163-175, abr., 2002).

CERLETTI, Alejandro. O ensino de filosofia como problema filosófico. Trad. Ingrid Müller Xavier. - Belo Horizonte: Autêntica Editora, 2009. 101 p.

DELEUZE, Gilles. Foucault. Trad. Cláudia Sant'Ana Martins. - 1. Ed. - São Paulo: Brasiliense, 1988.

EIZIRIK, Marisa F. A agonística foucaultiana. In.: Michel Foucault: um pensador do presente. - Ijuí: ed. Unijuí, 2005, p. 129-147.

FOUCAULT, Michel. A governamentalidade. In: Microfísica do Poder. - Rio de Janeiro: Graal,1979.

GADELHA, Sylvio. Biopolítica, governamentalidade e educação: introdução e conexões, a partir de Michel foucault. - Belo Horizonte: Autêntica Editora, 2009.

LOKCMANN, Kamila. Inclusão escolar: saberes que operam para governar a população; orientadora: Clarice Salete Traversini. Porto Alegre, 2010. Dissertação (mestrado) Universidade Federal do Rio Grande do Sul. Faculdade de Educação. Programa de Pós-Graduação em Educação, 2010, Porto Alegre, BR-RS. 